\title{
Penerapan Model Pembelajaran Problem Based Learning Untuk Meningkatkan Kemampuan Berpikir Kritis Siswa Kelas V Sekolah Dasar
}

\author{
Maulida Anggraina Saputri \\ Program Studi Pendidikan Guru Sekolah Dasar \\ Fakultas Keguruan Ilmu Pendidikan \\ Universitas Kristen Satya Wacana \\ Email:292017041@student.uksw.edu
}

\begin{abstract}
Abstrak
Tujuan Penelitian ini untuk menganalisis penerapan model Problem Based Learning (PBL) dalammeningkatkan berfikir kritis siswa kelas V Sekolah Dasar, dimana model PBL ini adalah model yang berbasis dengan permasalahan yang mampu meningkatkan cara berfikir kritis siswa. Pada Penelitian ini menggunakan Meta Analisis dengan langkah pertama yang harus dilakukan adalah dengan cara merumuskan masalah terlebih dahulu, kemudian mengumpulkan data yang hendak dianalisis melalui penelusuran google cendikia. Disini peneliti menggunakan sampel sebanyak 5 artikel yang subjeknya siswa kelas 5 Sekolah Dasar di 5 Sekolah Dasar, yaitu SD Negeri Kecandaran 1, SD Muhammadiyah, SD Negeri Mangunsari 2 Salatiga, SD Negeri Ledok 5 Salatiga, dan salah satu SDN di Kecamatan Cikampek, Kabupaten Karawang yang tidak disebutkan namanya. Peneliti menganalisis hasil penelitian menggunakan metode pembanding kuantitatif. Berdasarkan hasil analisis mengenai penggunaan model Problem Based Learning (PBL) dapat diperoleh hasil bahwa model ini dapat meningkatkan berfikir kritis siswa kelas V Sekolah Dasar mulai dari peningkatan terendah $0,61 \%$ sampai yang tertinggi sebesar $18,15 \%$.
\end{abstract}

Kata kunci: $P B L$, Berfikir Kritis, Sekolah Dasar.

\begin{abstract}
The purpose of this study was to analyze the application of the Problem Based Learning (PBL) model in improving the critical thinking of fifth grade students of elementary schools, where this PBL model is a problem based model that is able to improve students' critical thinking. In this study using Meta Analysis with the first step that must be done is to formulate the problem first, then collect the data to be analyzed through Google Scholar search. Here the researchers used a sample of 5 articles whose subjects were 5th grade elementary school students in 5 elementary schools, namely Kecandaran 1 Elementary School, Muhammadiyah Elementary School, Mangunsari 2 Public Elementary School Salatiga, Ledok 5 Salatiga State Elementary School, and one of the elementary schools in Cikampek District, Karawang Regency, which is not named. Researchers analyze the results of research using quantitative comparison methods. Based on the results of the analysis of the use of the Problem Based Learning (PBL) model, the results can be obtained that this model can improve the critical thinking of fifth grade students of elementary schools starting from the lowest increase of $0.61 \%$ to the highest of $18.15 \%$.
\end{abstract}

Keywords:PBL, Critical Thinking, Elementary School.

\section{PENDAHULUAN}

Kurikulum 2013 diberlakukan secara bertahap mulai tahun ajaran 2013/2014 melalui pelaksanaan terbatas, khususnya bagi sekolah yang sudah siap melaksanakannya dan sekolah yang memiliki nilai akreditasi "A". Tahun Ajaran 2013/ 2014, Kurikulum 2013 dilaksanakan secara terbatas untuk Kelas I dan Kelas IV Sekolah Dasar/ Madrasah Ibtida'iyah 
(SD/MI), Menurut (Imam, 2017) Kurikulum 2013 dirancang agar dapat menjawab kebutuhan zaman modern, kurikulum 2013 dalam pembelajarannya di kelas, guru dituntut untuk lebih kreatif dalam menyampaikan materi kepada siswanya. Selain itu, guru juga dituntut untuk lebih menekankan pada proses, bukan pada hasil. Tujuan dari hal tersebut adalah agar siswa sebagai sasaran utama perubahan kurikulum ini diharapkan akan mampu menjadi pribadi yang berkarakter. Selain itu Guru sebagai kepanjangan tangan dari pemerintah di sekolah, dalam pembelajarannya sekolah dituntut untuk menerapkan kemampuan berfikir kritis siswa , hal ini terwujud cepat tidak hanya untuk tuntutan pada kinerja guru dalam mengubah metode mengajar, tetapi juga peran dan tanggung jawab pendidik non formal dalam membiasakan anak-anak menerapkan berfikir kritis dalam pembelajaran.

Menurut

(Johnson, 2007:183)

berpikir kritis merupakan proses sistematis yang digunakan dalam kegiatan mental seperti pemecahan masalah, pengambilan keputisan, membujuk, menganalisis asumsi, dan melakukan penelitian ilmiah. Sedangkan menurut (Christina \& Kristin, 2017) Berpikir kritis merupakan kemampuan sesorang dalam menemukan informasi dan pemecahan sebuah masalah dari suatu masalah dengan cara bertanya kepada dirinya sendiri untuk menggali informasi tentang masalah yang sedang di hadapi. Jadi dapat disimpulkan bahwa Critical thinking (berpikir kritis) yaitu kemampuan siswa dalam berpikir kritis berupa bernalar, mengungkapkan, menganalisis dan menyelesaikan masalah. Di era reformasi critical thinking, juga digunakan untuk menangkal dan memfilter paham radikal yang dianggap tidak masuk akal. Kemampuan berpikir kritis biasanya diawali dengan kemampuan seseorang mengkritisi berbagai fenomena yang terjadi di sekitarnya, kemudian menilai dari sudut pandang yang digunakannya. Kemudian ia memposisikan dirinya, dari situasi yang tidak tepat menjadi situasi yang berpihak padanya. Kemampuan berpikir kritis sangat penting bagi siswa dalam melakukan pembelajaran. Pentingnya berpikir kritis bagi setiap siswa agar siswa dapat memecahkan segala permasalahan yang ada di dalam dunia nyata.

Dari permasalahan yang ditemukan, dibutuhkan perbaikan proses pembelajaran yang mampu meningkatkan kemampuan berpikir kritis dan hasil belajar peserta didik. Salah satu alternatif yang dapat digunakan yaitu dengan menerapkan model pembelajaran, salah satu model yang dapat diterapkan adalah model Problem Based Learning. Koeswanti (2018:7) menyatakan bahwa model pembelajaran Problem Based Learning membantu peserta didik dalam mengembangkan kecakapan memecahkan masalah, meningkatkan pemahaman dan pengetahuan, serta keaktifan dalam mendapatkan pengetahuan. Jadi Problem Based Learning adalah seperangkat model mengajar yang menggunakan masalah sebagai fokus untuk mengembangkan keterampilan pemecahan masalah, materi, dn pengetahuan diri.' (Hmelo-Silver, Serafino \& Cicchelli dalam Eggen \& Kauchak, 2012, hlm 307). Ditegaskan kembali oleh Tung (2015, hlm. 228) bahwa "pembelajaran ini melibatkan murid untuk memecahkan masalah melalui tahap-tahap metode ilmiah sehingga mereka dapat memelajari pengetahuan yang berhubungan dengan masalah tersebut dan sekaligus memiliki keterampilan untuk memecahkan masalah.Model pembelajaran yang menggunakan masalah nyata dalam kehidupan sehari-hari dan perlu banyak informasi yang relevan dan sesuai untuk menemukan proses pemecahan masalah dalam pembelajaran. Oleh karena itu model pembelajaran Problem Based Learning sangat ideal apabila diterapkan di Sekolah Dasar. Adapun langkah-langkah penerapan model Problem Based Learning (PBL) terdiri atas lima langkah utama yaitu sebagai berikut: "1) Orientasi peserta didik pada masalah; 2) Mengorganisasi untuk belajar; 3) Membimbing penyelidikan individual dan kelompok; 4) Mengembangkan dan menyajikan hasil karya; 5) Menganalisis.

\section{METODOLOGI PENELITIAN}

Jenis penelitian ini menggunakan Metode Meta-Analisis yang melibatkan hasil penelitian dari beberapa peneliti.Meta-Analisis adalah informasi terstruktur yang mendeskripsikan, menjelaskan, menemukan, atau setidaknya menjadi suatu informasi yang mudah untuk ditemukan kembali, digunakan, atau dikelola. Hasil penelitian dari beberapa peneliti didapat melalui penelusuran google cendikia atau google scholar. Disini peneliti 
menggunakan metode pembanding kuantitatif dalam menganalisis penerapan model pembelajaran problem based learning(PBL) untuk meningkatkan kemampuan berfikir kritis siswa kelas V Sekolah Dasar, dengan menggunakan 5 artikel.

$$
\text { Problem Based Learning }
$$

(PBL)merupakan model yang berbasis dengan permasalahan, dalam hal ini siswa dikenalkan dengan sebuah permasalahan dan diminta untuk aktif dalam menyelesaikan permasalahan tersebut. Dalam penyelesaiannya permasalahan itu, diminta untuk mengumpulkan informasi yang dapat mendukung dalam pemecahan masalah tadi dan kemudian dikembangkan agar dapat menyajikan suatu hasil karya dan diberikan evaluasi. Jadi problem based learning(PBL)merupakan salah satu model yang cocok digunakan untuk meningkatkan berfikir kritis siswa kelas 5 Sekolah Dasar karena model ini berbasis dengan permasalahan dan siswa diminta untuk menyelesaikan suatu permasalahan sampai menyajikan suatu hasil karya. Berdasarkan penjelasan tersebut, pada penelitian ini adalah untuk menganalisis kembali apakah model pembelajaran problem based learning(PBL) efektif dapat meningkatkan berfikir kritis siswa kelas V Sekolah Dasar?

\section{HASIL PENELITIAN DAN PEMBAHASAN}

Penelitian ini melibatkan 5 artikel jurnal tentang penerapan model pembelajaran Problem Based Learning (PBL) untuk meningkatkan berfikir kritis siswa kelas V Sekolah Dasar. Berikut ini hasil penelitian (artikel jurnal) yang diikutsertakan dalam penelitian analisis ini:

1). "Peningkatan kemampuan berpikir kritis dan hasil belajar matematika menggunakan model pbl pada siswa kelas v" oleh Bayu Saputro, Bambang Suteng Sulasmono, Eunice Widyanti Setyaningtyas. Dengan subjek siswa kelas V SD Negeri Kecandran 01 yang berjumlah 36 anak dengan sebaran 21 anak laki-laki dan 15 anak perempuan.

2). "Penerapan model problem based learning untuk meningkatkan berpikir kritis siswa kelas 5 pada mata pelajaran pkn di sd muhammadiyah kauman tahun 2016/ 2017" oleh Tri Siwi Septiana dan M. Ragil Kurniawan. Subjek penelitian adalah siswa kelas 5 B1 SD Muhammadiyah Kauman dengan jumlah 31 siswa.

3). "Peningkatan kemampuan berpikir kritis dan hasil belajar tematik muatan ipa melalui model problem based learning kelas 5 sd" oleh Ridha Unnafi Walfajri dan Nyoto Harjono. Dalam jurnal ini menggunakan sampel siswa kelas 5 SD N Mangunsari 02 Salatiga. Dengan jumlah siswa kelas 5 adalah 22 siswa. Siswa lakilaki berjumlah 13 dan siswa perempuan berjumlah 9 .

4). "Penerapan model problem based learning untuk meningkatkan kemampuan berpikir kritis siswa kelas $\mathrm{v}$ sdn ledok 5 tahun pelajaran 2018/2019" oleh Khintan Ustino Alita, Henny Dewi Koeswanti, Sri Giarti. Dalam jurnal ini menggunakan siswa kelas 5 sdn ledok 5 sebagai sample penelitian.

5). "Penerapan model problem based learning untuk meningkatkan kemampuan berpikir kritis pada pembelajaran ipa di sekolah dasar" oleh Shofiyah Maqbullah, Tati Sumiati, Idat Muqodas. Dalam penelitian jurnal ini menggunakan sampel 26 peserta didik dengan peserta didik laki-laki berjumlah 12 orang dan perempuan berjumlah 14 orang.

Hasil penelitian dari 5 artikel harus dianalisis dahulu dengan mengambil intinya Inti dari hasil penelitian berupa peningkatan berfikir kritis siswa kelas V Sekolah Dasar dengan menghitung selisih nilai sebelum dan sesudah pembelajaran menggunakan model Problem Based Learning (PBL). Berikut ini merupakan hasil dari analisis 5 data jurnal:

Tabel. 1 Hasil Analisis Model Pembelajaran Problem Based Learning (PBL)

\begin{tabular}{lccccc}
\hline \multirow{2}{*}{ No Judul Penelitian } & \multirow{3}{*}{ Peneliti } & \multicolumn{4}{c}{ Peningkatan Kemampuan Berfikir Kritis } \\
\cline { 3 - 5 } & & Sebelum & Sesudah & Gain & Gain (\%) \\
\hline
\end{tabular}




\begin{tabular}{|c|c|c|c|c|c|c|}
\hline 1 & $\begin{array}{l}\text { Peningkatan } \\
\text { kemampuan } \\
\text { berpikir kritis } \\
\text { dan hasil belajar } \\
\text { matematika } \\
\text { menggunakan } \\
\text { model pbl pada } \\
\text { siswa kelas v }\end{array}$ & $\begin{array}{l}\text { Bayu Saputro, } \\
\text { Bambang } \\
\text { Suteng } \\
\text { Sulasmono, } \\
\text { Eunice } \\
\text { Widyanti } \\
\text { Setyaningtyas }\end{array}$ & 60,06 & 72,22 & 12,16 & 20,24 \\
\hline 2 & $\begin{array}{l}\text { Penerapan model } \\
\text { problem based } \\
\text { learning untuk } \\
\text { meningkatkan } \\
\text { berpikir kritis } \\
\text { siswa kelas } 5 \\
\text { pada mata } \\
\text { pelajaran pkn di } \\
\text { sd } \\
\text { muhammadiyah } \\
\text { kauman tahun } \\
2016 / 2017\end{array}$ & $\begin{array}{lr}\text { Tri } & \text { Siwi } \\
\text { Septiana dan } \\
\text { M. Ragil } \\
\text { Kurniawan }\end{array}$ & 51,61 & 70,97 & 19,36 & 37,51 \\
\hline 3 & $\begin{array}{l}\text { Peningkatan } \\
\text { kemampuan } \\
\text { berpikir kritis } \\
\text { dan hasil belajar } \\
\text { tematik muatan } \\
\text { ipa melalui } \\
\text { model problem } \\
\text { based learning } \\
\text { kelas } 5 \text { sd }\end{array}$ & $\begin{array}{l}\text { Ridha Unnafi } \\
\text { Walfajri dan } \\
\text { Nyoto Harjono }\end{array}$ & 76,5 & 78,5 & 2 & 2,61 \\
\hline 4 & $\begin{array}{l}\text { Penerapan model } \\
\text { problem based } \\
\text { learning untuk } \\
\text { meningkatkan } \\
\text { kemampuan } \\
\text { berpikir kritis } \\
\text { siswa kelas v sdn } \\
\text { ledok } 5 \text { tahun } \\
\text { pelajaran } \\
\text { 2018/2019 }\end{array}$ & $\begin{array}{l}\text { Khintan } \\
\text { Ustino Alita, } \\
\text { Henny Dewi } \\
\text { Koeswanti, Sri } \\
\text { Giarti }\end{array}$ & 83 & 87 & 5 & 6,01 \\
\hline 5 & $\begin{array}{l}\text { Penerapan model } \\
\text { problem based } \\
\text { learning untuk } \\
\text { meningkatkan } \\
\text { kemampuan } \\
\text { berpikir kritis } \\
\text { pada } \\
\text { pembelajaran ipa } \\
\text { di sekolah dasar }\end{array}$ & $\begin{array}{l}\text { Shofiyah } \\
\text { Maqbullah, } \\
\text { Tati Sumiati, } \\
\text { Idat Muqodas }\end{array}$ & 67,88 & 76,15 & 8,27 & 12,18 \\
\hline
\end{tabular}

Model Problem Based Learning (PBL)

67,81

76,96

9,35

15,6 
Tabel. 2 Paired Samples Statistics

\begin{tabular}{|c|c|c|c|c|c|}
\hline \multicolumn{6}{|c|}{ Paired Samples Statistics } \\
\hline & & Mean & $\mathrm{N}$ & Std. Deviation & Std. Error Mean \\
\hline \multirow{2}{*}{ Pair 1} & Sebelum & 67.8100 & 5 & 12.53754 & 5.60696 \\
\hline & Sesudah & 76.9680 & 5 & 6.36743 & 2.84760 \\
\hline \multicolumn{6}{|c|}{ Tabel. 3 Paired Samples Correlations } \\
\hline \multicolumn{6}{|c|}{ Paired Samples Correlations } \\
\hline & & & & Correlation & Sig. \\
\hline Pair 1 & Sebe & \&Sesudah & & .730 & .162 \\
\hline
\end{tabular}

Tabel. 4 Samples Test

\begin{tabular}{|c|c|c|c|c|c|c|c|c|c|}
\hline \multicolumn{10}{|c|}{ Paired Samples Test } \\
\hline & & \multicolumn{5}{|c|}{ Paired Differences } & \multirow[t]{3}{*}{$\mathrm{t}$} & \multirow[t]{3}{*}{$\mathrm{df}$} & \multirow{3}{*}{$\begin{array}{l}\text { Sig. } \\
(2- \\
\text { tailed })\end{array}$} \\
\hline & & \multirow[t]{2}{*}{ Mean } & \multirow[t]{2}{*}{$\begin{array}{c}\text { Std. } \\
\text { Deviation }\end{array}$} & \multirow[t]{2}{*}{$\begin{array}{l}\text { Std. } \\
\text { Error } \\
\text { Mean }\end{array}$} & \multicolumn{2}{|c|}{$\begin{array}{l}\text { 95\% Confidence } \\
\text { Interval of the } \\
\text { Difference }\end{array}$} & & & \\
\hline & & & & & Lower & Upper & & & \\
\hline $\begin{array}{c}\text { Pair } \\
1\end{array}$ & $\begin{array}{l}\text { Sebelum - } \\
\text { Sesudah }\end{array}$ & -12.75800 & 1.96439 & .87850 & -15.19711 & -10.31889 & -14.522 & 4 & .000 \\
\hline
\end{tabular}

Berdasarkan analisis data menggunakan SPSS 20 for Windows dengan uji Paired Sample Test melalui perbandingan nilai sebelum dan sesudah mengenai penggunaan model Problem Based Learning dapat diperoleh hasil bahwa model ini dapat meningkatkan berfikir kritis siswa kelas V Sekolah Dasar mulai dari peningkatan terendah $0,61 \%$ sampai yang tertinggi sebesar $18,15 \%$.

Berdasarkan hasil Output Paired Sample $\mathrm{T}$ Test pada tabel 2 menunjukkan bahwa model pembelajaran Problem Based Learning (PBL)dapat meningkatkan kemampuan berfikir kritis siswa kelas V Sekolah Dasar, dengan nilai rata-rata 67.8100 menjadi 76.9680. pada tabel 3 menunjukkan bahwa terdapat korelasi antara nilai rata-rata kemampuan berfikir kritis siswa sebelum menggunakan model pembelajaran Problem Based Learning (PBL) dan sesudah menggunakan model pembelajaranproblem Based Learning (PBL). Hal ini ditunjukkan oleh nilai Correlation pada tabel 3 sebesar 0,730 dengan tingkat korelasi tinggi.

Hasil uji hipotesis dengn $\mathrm{H}_{0}=$ tidak terdapat perbedaan yang signifikan antara berfikir kritis siswa kelas V Sekolah Dasar sebelum dan sesudah menggunakan model Problem Based Learning dan $\mathrm{H}_{1}=$ terdapat perbedaan yang signifikan antara berfikir kritis siswa kelas V Sekolah Dasar sebelum dan sesudah menggunakan model Problem Based Learning. Berdasarkan hasil Uji Paired Sample Test pada tabel 4 menunjukkan bahwa nilai Sig.(2-tailed) yaitu .000 $<(0.05)$ dan $\mathrm{t}_{\text {hitung }}=-14.522<\mathrm{t}_{\text {tabel }}=2.132$ sehingga dapat 
dikatakan bahwa $\mathrm{H}_{0}$ ditolak. jadi, dapat disimpulkan bahwa terdapat perbedaan yang signifikan antara antara berfikir kritis siswa kelas V Sekolah Dasar sebelum dan sesudah menggunakan model Problem Based Learning.Berikut ini merupakan kriteria dalam mengambil keputusan:

1. Menggunakan koefisien Sig. Dengan ketentuan:

a. Jika nilai sig. hitung (probabilitas) < 0,05 maka $\mathrm{H}_{0}$ ditolak.

b. Jika nilai sig. hitung (probabilitas) > 0,05 maka $\mathrm{H}_{0}$ diterima.

2. Menggunakan koefisien $\mathrm{t}$ hitung dengan ketentuan:

a. Jika nilai t hitung $>$ maka $\mathrm{H}_{0}$ ditolak.

b. Jika nilai t hitung < maka $\mathrm{H}_{0}$ diterima. Berdasarkan hasil-hasil penelitian dapat dituliskan bahwa hasil penelitian peningkatan berfikir kritis siswa kelas V Sekolah Dasar yang telah dilakukan memiliki presentase yang berbeda-beda, selain itu proses pembelajaran yang dilakukan oleh setiap guru dalam kelima artikel tersebut memiliki perbedaan dalam menerapkan model pembelajaran Problem Based Learning (PBL) hal itu juga dapat mempengaruhi peningkatan berfikir kritis siswa.

\section{SIMPULAN}

Dari hasil meta-analisis pada penelitian ini disimpulkan bahwa penggunaan model pembelajaran Problem Based Learning (PBL) efektif untuk meningkatkan berfikir kritis siswa, karena model ini berbasis masalah dengan menjelasakan dan memberikan motivasi untuk memecahkan masalah, kemudian mengorganisasikan siswa dalam tugas belajar yang berhubungan dengan permasalahan tersbut, selain memotivasi juga memberikan dorongan untuk siswa mengumpulkan informasi sehingga dapat melaksanakan eksperimen dengan cara menyiapkan karya yang sesuai yang pada akhirnya dapat dievaluasi oleh guru untuk mendapatkan penilaian atau tambahan dari guru. Berdasarkan hasil analisis mengenai penggunaan model Problem Based Learning dapat diperoleh hasil bahwa model ini dapat meningkatkan berfikir kritis siswa kelas V Sekolah Dasar mulai dari peningkatan terendah $0,61 \%$ sampai yang tertinggi sebesar $18,15 \%$.

\section{DAFTAR PUSTAKA}

Alita, Khintan Ustino,dkk. 2019. penerapan model problem based learning untuk meningkatkan kemampuan berpikir kritis siswa kelas $v$ sdn ledok 5 tahun pelajaran 2018/2019. Jurnal Basicedu Volume 3 Nomor 1 Tahun 2019 Halaman 169- 173 e-ISSN 2580-1147. 30 Maret 2020 pukul 15:13 WIB.

Christina, L. V., \& Kristin, F. (2017). Efektivitas Model Pembelajaran Tipe Group Investigation (Gi) Dan Cooperative Integrated Reading and Composition (Circ) Dalam Meningkatkan Kreativitas Berpikir Kritis Dan Hasil Belajar Ips Siswa Kelas 4. Scholaria: Jurnal Pendidikan Dan Kebudayaan, 6(3), 217.

Johnson, E.B. (2007). Contextual Teaching and Learning ( Menjadikan Kegiatan Belajar Mengajar Mengasyikan dan Bermakna). Mizan Learning Center (MLC). Bandung.

Maqbullah , Shofiyah, dkk. 2018. penerapan model problem based learning untuk meningkatkan kemampuan berpikir kritis pada pembelajaran ipa di sekolah dasar. Metodik Didaktik Vol. 13 No. 2

Nigrum, Elwin Sulitya, Ahmad Yusuf Sobri. 2015. implementasi kurikulum 2013 di sekolah dasar

Saputro, Bayu, dkk. 2019. peningkatan kemampuan berpikir kritis dan hasil belajar matematika menggunakan model pbl pada siswa kelas $v$. Jurnal Pendidikan Tambusai Volume 3 Nomor 2 e-ISSN: 2614-3097.

Septiana, Tri Siwi, M Ragil Kurniawan. 2018. Penerapan model problem based learning untuk meningkatkan berpikir kritis siswa kelas 5 pada mata pelajaran pkn di sd muhammadiyah kauman tahun 2016/2017. Fundamental Pendidikan Dasar Vol. 1 No. 1 p.9 4 105 e- ISSN : 2614-1620.

Upayanto, Imam Dwi. 2017. Pelaksanaan proses pembelajaran kurikulum 2013 sd negeri 4 krandegan. Jurnal Pendidikan Guru Sekolah Dasar Edisi 1. 
Walfajri, Ridha Unnafi, Nyoto Harjono. 2019. Peningkatan kemampuan berpikir kritis dan hasil belajar tematik muatan ipa melalui model problem based learning kelas 5 sd. Jurnal Basicedu Volume 3 Nomor 1 Tahun 2019 Halaman 16- 20. e-ISSN 2580-1147. 